\title{
0 Ministério dos Negócios Estrangeiros Português e a Integração Europeia (1951-1986)
}

1. Doutora em História Contemporânea pela Faculdade de Ciências Sociais e Humanas da Universidade Nova de Lisboa. Desde 2008, é investigadora nessa Faculdade na área de História da Integração Europeia, área na qual tem publicado, sendo atualmente autora de 24 artigos com arbitragem científica e de 14 capítulos de livros, coordenadora de dez e único autor de três. Organizou mais de três dezenas de eventos científicos e tem participado em diversos projetos de investigação, nacionais e internacionais. Lisboa/Portugal ORCID: 0000-0003-3206-8475 (iD)

2. Doutora em Altos Estudos Contemporâneos (História Contemporânea, Estudos Internacionais Comparativos) Faculdade de Letras da Universidade de Coimbra. Possui um Mestrado em Estudos Europeus pela Faculdade de Letras da Universidade de Coimbra. É Investigadora Integrada do Centro de

Estudos Interdisciplinares do Século XX da Universidade de Coimbra - CEIS20, Coordenadora Científica do Grupo de Investigação Europeísmo, Atlanticidade e Mundialização do CEIS20-UC. Coimbra/Portugal. ORCID: 0000-00032403-5147 (D)

\section{The Portuguese Foreign Affairs Office and European Integration (1951-1986)}

\begin{abstract}
Recebido em: 14 de maio de 2018
\end{abstract}
Aprovado em: 4 de agosto de 2018

DOl: 10.5752/P.2317-773X.2019v7.n1.p110

\author{
Alice Cunha ${ }^{1}$ \\ Isabel Maria Freitas Valente ${ }^{2}$
}

\section{RESUMO}

Após os tormentos da II Guerra Mundial, a Europa irá reinventar-se a si própria, sendo que uma dessas formas se reveste nos comummente designados movimentos de cooperação e de integração europeia, com os quais Portugal também se envolveria. Tendo como enquadramento a posição do Estado português para com a integração europeia, este artigo analisa especificamente o papel do Ministério dos Negócios Estrangeiros (MNE) no que diz respeito à integração europeia. O recorte temporal vai desde a Declaração Schuman, em 1951, até à adesão de Portugal à Comunidade Económica Europeia, em 1986. Conclui-se que, como seria expectável, o MNE serviu as diretrizes do regime no poder, cumprindo instruções, mas também conferindo o seu cunho, o que é particularmente visível na ação de um conjunto de diplomatas pró-europeus. No geral, sempre se batalhou, inclusive no MNE, pela "Europa económica" e apenas após 1976 também pela "Europa política”.

Palavras-chave: diplomacia; integração europeia; Ministério dos Negócios Estrangeiros; Portugal

\begin{abstract}
After the devastation of the II World War, Europe will reinvent itself, namely by the commonly known movements of cooperation and European integration, with which Portugal also got involved in. Bearing in mind the official position of the Portuguese government towards European integration, through the time, this article analyzes specifically the role of the Portuguese Foreign Affairs Office regarding European integration. The time frame of this article goes from the Schuman Declaration in 1951 until the Portuguese accession to the European Economic Community in 1986. We conclude that, as expected, the Foreign Office served the regime's position on the matter, fulfilling instructions, but also adding its own vision, which was particular visible in some pro-European diplomats. Overall, the Foreign Office always battled to become a member of the "economic Europe" and after 1976 also of the "political Europe".
\end{abstract}

Keywords: diplomacy; European integration; Foreign Affairs Office; Portugal 
Introdução

Após os tormentos da guerra, a Europa irá reinventar-se a si própria, sendo que uma dessas formas se reveste nos comummente designados movimentos de cooperação e de integração europeia, com os quais Portugal também se envolverá e nos quais o Ministério dos Negócios Estrangeiros (MNE) português participará.

Salvo raras exceções (HOCKING; SPENCE, 2002; HOCKING, 1999), a literatura especializada estrangeira (de Ciência Política, Relações Internacionais e História Contemporânea), não tem dedicado especial atenção ao papel dos ministérios dos Negócios Estrangeiros na formulação, condução e execução dos assuntos europeus. O mesmo se aplica à literatura portuguesa, da qual apenas se conhece um artigo (CORREIA, 2006, p. 29-81), que aborda esta questão com mais detalhe. Assim, parece pertinente analisar a intervenção do MNE no que diz respeito à integração europeia e à participação do país nesse processo, precisamente no centenário de nascimento do Embaixador Calvet de Magalhães ${ }^{3}$ e nos 30 anos da assinatura do Acto de Adesão. O recorte temporal proposto vai desde a Declaração Schuman, em 1951, até à adesão de Portugal à Comunidade Económica Europeia (CEE), em 1986, a fim de aferir o grau de afastamento e/ou de envolvimento do MNE nesse âmbito.

Este artigo é baseado em pesquisa arquivística, tendo sido consultada documentação das seguintes fontes: Arquivo Histórico-Diplomático do Ministério dos Negócios Estrangeiros (AHD-MNE), Arquivo Particular de Calvet de Magalhães, do extinto Instituto de Estudos Estratégicos Internacionais, Arquivos da Organização para a Cooperação e Desenvolvimento Económico (OCDE), Public Record Office (National Archives), Centro de Documentação Europeia da Universidade Católica Portuguesa (CDE-UCP) - Espólio Ernâni Rodrigues Lopes (ERL). Recorre-se também a entrevistas realizadas entre 2010 e 2012 com alguns dos responsáveis políticos e diplomáticos que participaram nas negociações de adesão.

Numa primeira parte, tentar-se-á demonstrar que a aproximação de Portugal aos movimentos de cooperação e de integração regional pós-guerra resultou principalmente da conjugação de vários esforços e iniciativas pessoais de funcionários de topo, mais do que do resultado de uma política consciente governamental, como é aliás corroborada por alguns deles (Calvet de Magalhães, nomeadamente). Neste sentido, o aparecimento e crescimento de uma corrente internacionalista pró-europeia no MNE, durante o Estado Novo (1933-1974), é talvez um dos aspectos mais interessantes da história da diplomacia portuguesa no pós II Guerra.

De facto, os embaixadores Ruy Teixeira Guerra e José Thomaz Calvet de Magalhães foram dois dos protagonistas (e não raras vezes assumiram o que consideraram ser o interesse do país, sem o apoio explícito do Governo) da internacionalização de Portugal. Principalmente, são responsáveis pelo envolvimento do País no processo de construção europeia, mesmo que inicialmente aquele se apresentasse sob a forma de cooperação.

Já depois do 25 de Abril de 1974, com a instauração progressiva de um regime democrático no País, esse movimento de aproximação à Europa continuou e a adesão à CEE foi tomada como uma espécie de
3. José Thomaz Cabral Calvet de Magalhães (1915-2004) foi um diplomata português, cujo nome e carreira ficaram associados à história da integração do país nos movimentos de cooperação e de integração europeia do pós II Guerra Mundial. Em 1959, chefiou a delegação portuguesa durante a convenção negocial do Tratado de Estocolmo, que criou a Associação Europeia de Comércio Livre e, em 1960, foi nomeado Representante junto das Comunidades Europeias, tendo em 1962 sido nomeado Representante Permanente e Chefe da Delegação portuguesa junto da Comunidade Económica Europeia. 
desígnio nacional. Tendo isso em vista, mesmo antes das negociações de adesão começarem, afigurava-se indispensável saber, interna e externamente, quem negoceia e a que nível (técnico ou ministerial), bem como quem coordena as negociações, se a Presidência do Conselho de Ministros, se o MNE, se o Ministério das Finanças e do Plano. Com isso, tem início toda uma movimentação governamental no sentido da definição da estrutura negocial portuguesa, o que será analisado numa segunda parte deste artigo, assim como será explicado o maior ou menor grau de intervenção do MNE nessas negociações.

O desenho da pesquisa foi orientado, em parte, pelo método do "process tracing" (ou mapeamento de processo) no sentido em que, partindo de um estudo de caso específico (o MNE e a integração europeia), promove a análise de ações e de mecanismos específicos que contribuem para uma possível explicação de certas relações causais, que culminam em determinadas decisões, como a da adesão à EFTA e, mais tarde, à CEE.

\section{Aparecimento de uma corrente pró-europeia e internacionalista} no MNE durante o Estado Novo

Numa época em que o governo português defendia que o futuro de Portugal estava indissociavelmente ligado à sua soberania sobre os territórios ultramarinos, um restrito grupo de diplomatas (como Ruy Teixeira Guerra e Calvet de Magalhães) pensava de forma diversa e considerava que a ligação à Europa, esteio fundamental da cultura portuguesa, era essencial para o futuro desenvolvimento económico e social nacional.

$\mathrm{Na}$ ótica de Calvet de Magalhães, "a obra da nossa aproximação das instituições europeias nos seus primeiros passos resultou principalmente da conjugação de vários esforços e iniciativas pessoais, mais do que resultado de uma política consciente governamental, e a essa obra me achei pessoalmente ligado nalguns momentos cruciais dessa aproximação. (...) [a nível oficial] não só não existia na época qualquer entusiasmo por parte do Governo Português pela ideia de uma união europeia, como até existia uma marcada hostilidade e até descrença acerca da viabilidade de quaisquer iniciativas nesse sentido" (MAGALHÃES, 1981, p. 44-45).

De facto, numa ação discreta, mas persistente, Teixeira Guerra e Calvet de Magalhães exercem, o primeiro, a partir de 1948, e o segundo de 1956, notável influência no sentido de aproximar Portugal aos grandes organismos económicos europeus que surgiram no pós-guerra.

Entre eles, há que salientar o envolvimento, desde sempre, nas negociações de aproximação ao processo europeu, inicialmente de cooperação (na OECE e Plano Marshall) e mais tarde de construção da própria união europeia (EFTA, CEE). Outro exemplo esclarecedor a ser considerado é o facto de Calvet de Magalhães ter exercido, em simultâneo, as funções de chefe e representante da OECE na Comissão Técnica de Cooperação Económica Europeia (CTCEE) e desta na OECE/OCDE.

É neste contexto que a força anímica destes diplomatas se revela através de um contributo inestimável para a definição e adoção de uma das estratégias de política externa de Portugal mais frutuosas - a da inter- 
nacionalização da economia portuguesa através da plena participação nas instituições internacionais e europeias do pós-guerra.

Para esclarecer este ponto deve ter-se em conta o facto que, em 1956, Calvet de Magalhães foi colocado em Paris onde conseguiu que lhe fossem abertas as portas de algumas das mais importantes instituições europeias de cooperação, onde desenvolveu, como veremos, uma intensa atividade diplomática e onde exercitou o seu conceito de diplomacia económica. Relativamente a esta questão, João Rosas afirma que foi com:

\footnotetext{
"Calvet de Magalhães que o Ministério dos Negócios Estrangeiros começou a interessar-se pela parte económica dos acordos internacionais. Já antes de ser Secretário-Geral do MNE, logo no início da sua carreia, Calvet teve uma ação muito importante na intervenção do MNE nos acordos económicos. Conseguiu reunir uma equipa de diplomatas com formação económica e com isso criou o alfobre daquilo que veio a ser a diplomacia económica do MNE que passou a tomar a seu cargo a parte económica dos acordos internacionais. Até então, os Embaixadores não se interessavam pela parte económica. Esta era designada, nos corredores do Palácio das Necessidades [sede do MNE], como cascalho. Aliás, na minha opinião, esta foi uma das duas razões que tornou a ação de Calvet de Magalhães, enquanto diplomata, excecional. A segunda foi a aproximação e abertura à Europa que ele proporcionou a Portugal. Nessa área a sua capacidade negocial floresceu"4. (ROSAS, 2010)
}

O êxito que Calvet de Magalhães teve na execução dos seus objetivos, conseguindo a tão almejada (e quase inexequível) participação portuguesa nos movimentos de cooperação que então fervilhavam na Europa é notório. A sua nomeação, em abril de 1959, para o cargo de representante de Portugal na Comunidade Europeia do Carvão e do Aço, e para a chefia da delegação portuguesa na maior parte das negociações que, durante $o$ ano de 1959, deram origem à EFTA, são disso exemplo.

À luz do que foi dito, pode agora explicitar-se como a história da aproximação/integração portuguesa a estes organismos internacionais foi marcada pela política de reserva de Salazar, por compromissos reais e pela ação persistente, de grande acuidade e eficiência dos diplomatas Teixeira Guerra e Calvet de Magalhães que inauguram uma corrente internacionalista e pró-europeia no MNE. Na verdade, este facto constitui, talvez, um dos dados mais interessantes da História Diplomática portuguesa do pós-guerra.

É nesta linha que se pode referir que num primeiro momento, apesar de Portugal participar ativamente nas diversas ações destinadas à elaboração e concretização do Plano Marshall, o governo português rejeita a possibilidade de aceitar auxílio financeiro americano através do Plano Marshall. No entanto, a decisão de não aceitar o auxílio financeiro americano não implicou qualquer alteração na qualidade que Portugal detinha enquanto país participante. Portugal continuou a participar nas reuniões e atividades dos países europeus e foi membro fundador da OECE 5 .

É porta-voz dessa posição portuguesa ${ }^{6}$ o Ministro dos Negócios Estrangeiros, Caeiro da Matta. Nela, Portugal mostra bem que as convicções políticas e ideológicas do regime prevaleciam sobre as novas realidades internacionais. Deste modo, o governo pretendia manter o país autónomo, do ponto de vista económico, mas a verdade é que Portugal dependia, em grande medida, dos fornecimentos do exterior. Seria esta grande dependência externa que colocaria limites à autonomia e a auto-
4. Entrevista a João Rosas, Rio de Janeiro, 20 de junho de 2010.

5. AHD-MNE, 2. ${ }^{\circ}$ P., A.40, M.238.

6. AHD-MNE, 2P., A.39, M.53 
7. José Gonçalo Corrêa de Oliveira (1921-1976) foi Secretário de Estado do orçamento e do comércio (de 21 de julho de 1955 a 4 de maio de 1961). Ministro da Presidência (de 22 de junho de 1961 a 19 de março de 1965). Ministro da Economia de Salazar e Marcello Caetano (de 19 de março de 1965 a 27 de março de 1969). Foi um dos principais peritos em comércio português de 1944 a 1955. Esteve ligado a todas as principais negociações da OECE foi responsável pela coordenação das negociações que levaram à constituição da EFTA.

8. AHD, PEA-M 309

9. AHD-OECE, $2^{\circ}$ Piso ARM7M.294.

10. Como escreve Nicolau Andresen Leitão em Estado Novo, Democracia e Europa. 1947-1986, "José Calvet de

Magalhães foi, a seguir à guerra, 0 diplomata mais importante nas negociações europeias" (Leitão, 2007).

11. AHD-MNE, 2. ${ }^{\circ}$ P., A.6, M.439 cracia tão ansiadas por Salazar.

Assim, foi num contexto de potenciais vantagens de cooperação económica que Salazar aceitou os benefícios do Plano Marshall (24 de novembro de 1948) e que Portugal integrasse a OCDE e posteriormente a EFTA. O País começa a beneficiar desses fundos a partir do segundo exercício do Plano (1949-1950). Portugal recebe ainda ajuda direta do fundo durante o terceiro exercício do Plano Marshall (1950-1951).

Pode dizer-se que é notória a correlação entre o agravamento da situação económica e financeira de Portugal e a decisão de alterar a posição inicialmente defendida de dispensar o auxílio financeiro Marshall.

É óbvio que, perante esta conjuntura, o governo português empenhar-se-ia para que o país fosse contemplado na distribuição dos créditos americanos. Para tal recorreria aos bons ofícios dos seus representantes diplomáticos, devendo neste contexto, e nesta primeira fase, sublinhar-se a importância da ação e dos esforços que Teixeira Guerra envidou junto do governo norte-americano e da administração do Plano Marshall para conseguir o máximo de auxílio financeiro para Portugal.

Por outro lado, a aventura europeia de Portugal contará, neste mesmo período cronológico em que se enquadra esta análise, com um terceiro ator para quem ganhava sentido e particular interesse a política de liberalização e internacionalização, leia-se europeização do País. Trata-se de Corrêa d' Oliveira, ${ }^{7}$ então funcionário do Ministério da Economia e nosso representante no Comité do Comércio, principal órgão da OECE. Corrêa d' Oliveira granjeou a admiração e simpatia de Salazar. A confiança que o governo depositava nele, muito em particular em matérias de comércio externo, conjugadas com as relações de confiança que Corrêa de Oliveira desenvolveu com importantes figuras da vida política europeia contribuíram muito para "permitir que os funcionários que se ocupavam desse sector pudessem dispor do apoio político necessário para o sucesso das suas diligências" (Magalhães, 1981, p. 41) durante um período em que, como sabemos, a vertente atlântica e fundamentalmente o ultramar ganham peso na condução da política externa portuguesa.

A Circular sobre a Integração Europeia para as Missões Diplomáticas do Conselho de Ministros ${ }^{8}$, de 6 de março de 1953, é disso exemplo.

No entanto, "nos assuntos europeus a Inglaterra continuará a ser a referência fundamental. De tal modo que Portugal seguirá de perto as posições britânicas nesta matéria até à entrada na EFTA como membro fundador" (Teixeira e Pinto, 2007, p. 17).

Assim, quando em 1956 os britânicos propuseram na OECE a criação de uma Zona de Livre Câmbio europeia e informaram Portugal, de forma unilateral, que apenas os países industrializados da organização participariam desta zona e que o país, devido ao seu atraso", não poderia fazer parte deste projeto, o governo português reage com "desusada energia à atitude britânica que, diga-se de passagem, foi um tanto prepotente e sobretudo inábil" (MAGALHÃES, 1991, p. 138).

Ora, é neste contexto histórico, político e económico que Calvet de Magalhães, enquanto chefe da delegação portuguesa junto da OECE, ${ }^{10}$ travará 'uma dura batalha' contra a atitude britânica que pretendia excluir Portugal de uma Zona de Comércio Livre ${ }^{11}$ onde esta- 
riam incluídos os países que constituíam os nossos principais mercados de exportação.

Na sequência da proposta britânica foi criado um grupo de trabalho n. ${ }^{\circ} 17$ (em junho de 1956) para estudar a viabilidade da iniciativa, sendo o País representado por Calvet de Magalhães. As posições tomadas ${ }^{12}$ pelo delegado português durante a reunião e consubstanciadas no seu primeiro relatório ${ }^{13}$ constituíram o guião de atuação do governo português durante as negociações para a criação da Zona de Comércio Livre. A argumentação é pertinente: Portugal pretende a sua entrada na zona de comércio livre ao abrigo de um regime especial pois considerava-se um país em vias de desenvolvimento.

É conveniente lembrar, a propósito, a criação (já depois do relatório do grupo 17 estar concluído, mas não difundido) de uma "comissão encarregada do estudo dos problemas relativos à criação e funcionamento da zona de comércio externo, de 5 de dezembro de 1956, que teve como Presidente Corrêa de Oliveira, então Subsecretário de Estado do Orçamento, e como vogais o Embaixador Teixeira Guerra, Director-Geral dos Negócios Económicos, Tovar de Lemos, Presidente da Comissão Técnica de Cooperação Económica Externa, Fernando Alves Machado, Presidente da Comissão de Coordenação Económica, Carlos Câmara Pestana, Director-Geral das Alfândegas e Isabel Magalhães Collaço (...) elaboraram um relatório que ficou ultimado em 28 de janeiro seguinte. Este trabalho serviu de base à atuação portuguesa nas negociações iniciadas no seio da OECE” (MAGALHÃES, 1991, p. 138-139).

Torna-se necessário, sem dúvida, referir que a análise desenvolvida no relatório de Calvet de Magalhães, fornece os principais argumentos da posição portuguesa e, muito concretamente, do discurso da delegada portuguesa no grupo de trabalho n.17, Isabel Magalhães Collaço, a 26 de novembro de $1956^{14}$.

Em 17 de outubro de 1957 foi criada a Comissão Intergovernamental ou Comissão Maulding para dar execução às conclusões dos grupos de trabalho. Portugal faz-se representar por Corrêa de Oliveira e perante a posição firme e bem fundamentada de Portugal a comissão viu-se forçada a criar um grupo de trabalho para estudar o caso português.

Os membros desta comissão e alguns técnicos acompanhados por Calvet de Magalhães e pelo grupo de trabalho português, visitaram Portugal $^{15}$, finalizando o seu relatório, que ficou conhecido por 'Relatório Melander", a 22 de outubro de 1958. Nesse relatório aceitavam-se todas as pretensões portuguesas, no entanto, não chegou a ser discutido na Comissão Maulding porque os seus trabalhos foram adiados sine die, a partir de 14 de novembro, em consequência do veto de De Gaulle à continuação das negociações.

Ora, este relatório viria a ter uma importância vital nas negociações que se seguiram ao fracasso da Comissão Maulding e que estariam na base da criação da EFTA e da integração portuguesa, enquanto membro fundador desta pequena Zona de Comércio Livre.

Neste quadro não deixa de ser importante sublinhar as palavras de Luís Figueira a este propósito: "Quando as negociações da Zona Maudling se goraram e surgiu a iniciativa britânica de, perante a existência
12. Relembre-se que, uma vez mais, Lisboa não deu nenhuma indicação precisa de como proceder nesse fórum. Atitude que era, aliás, muito frequente.

13. AHD-MNE, OECE, 2P, 61, M.295, P.3.

15. AHD-MNE, 2. ${ }^{\circ}$., A. 7, M.550.

14. AHD-MNE, 2. P.A. 56, M.296 
já efetiva da CEE, criar uma pequena zona de comércio livre dos restantes seis países desenvolvidos (...), da qual era intenção excluir-nos dado o nosso atraso económico, viemos afinal participar nas reuniões mais ou menos secretas ou informais que então tiveram lugar (de cuja realização nem sequer, aliás, nos fora dado conhecimento) em resultado da ação conjugada dos Embaixadores Calvet de Magalhães, então nosso Representante Permanente na OECE, e Ruy Teixeira Guerra, director geral dos Negócios Económicos do MNE. (...) Foi-nos possível, mercê de uma ação diplomática atenta e eficiente, baseada apenas no prestígio pessoal que os nossos dois tradicionais representantes haviam sabido granjear, não ficar de fora num processo que se antevia importante. É que foi destas reuniões que veio, sem demora, a resultar o processo de negociação que conduziu à criação da EFTA” (FIGUEIRA, 2003, p. 46).

Na sequência do veto do governo gaullista anunciado pelo Ministro da Informação francês, Jacques Soustelle, a 14 de novembro de 1958, é agendada uma reunião, em Genebra, para discutir e analisar as consequências da suspensão das negociações. Uma vez que o relatório Melander não chegou a ser debatido pelo Comité Maudling, Portugal não foi convidado para esta reunião.

Calvet de Magalhães ao ter conhecimento desta situação alerta, de imediato, Corrêa d’Oliveira, então Secretário de Estado do Comércio, para a importância vital de Portugal estar presente, em Genebra, pois corria-se o risco de ficarmos excluídos dos dois grandes grupos económi$\cos$ da Europa. O que teria graves consequências para as nossas exportações e para a economia portuguesa, em geral. Concordando com os argumentos do nosso Embaixador, Corrêa d'Oliveira estimula todas as diligências feitas por Calvet de Magalhães no sentido de contactar diretamente os responsáveis suíços.

Assim, Calvet de Magalhães em ação concertada com o Director-Geral dos Negócios, Teixeira Guerra, pressiona o Ministro Suíço, Hans Shaffner, para que Portugal participe na reunião de 1 de dezembro de 1958. Perante esta pressão, a presença portuguesa é aceite e cabe a Calvet de Magalhães e a Teixeira Guerra comparecerem na reunião, em Genebra $^{16}$.

Neste contexto, o Embaixador Siqueira Freire, questiona se "teríamos sido admitidos na EFTA se não tivéssemos estado presentes na OECE? Teríamos podido alcançar os termos em que assinámos o Acordo de 1972 com a CEE se não estivéssemos na EFTA? Teríamos podido pedir já a adesão como membros de pleno direito às Comunidades se não tivéssemos adquirido a imagem e a longa experiência da integração europeia adquiridas na EFTA e na vivência do Acordo Portugal-CEE de 1972?” (FREIRE, 1981, p. 21).

$\mathrm{Na}$ verdade, a importância do conhecimento adquirido nos dois anos de negociações para a ZCL bem como a participação de Portugal no Plano Marshall e, por via disso, nas organizações e nos organismos económicos que se foram sucedendo, como por exemplo, a OECE, UEP, OCDE, foram determinantes na modernização da economia portuguesa e na aproximação do país à Europa e fundamentais para o êxito da entrada de Portugal na EFTA. 
Deve acentuar-se, porém, que as negociações não foram fáceis para Portugal e sem o Relatório Melander, como escreveu Calvet de Magalhães, o País "teria fracas hipóteses de se tornar membro da EFTA" (MAGALHÃES,1988, p. 46).

Calvet de Magalhães chefiou a delegação portuguesa em todas as reuniões, a nível de funcionários, que se realizaram em Estocolmo e Saltsjöbaden, entre 17 de março e 1 de outubro de 1959. Sendo substituído pelo Embaixador Teixeira Guerra na última reunião desta natureza que teve lugar em novembro desse ano, por ter sido chamado a Paris no âmbito da transformação da OECE na atual OCDE.

As posições e pretensões portuguesas concretizam-se na última ronda negocial de 1959, em Estocolmo. Nela, Portugal alcança a vitória em todas as frentes. Segundo Corrêa d'Oliveira, "fazemos parte de um grupo de países que lidera a política europeia com direitos iguais, mas sem obrigações iguais" ${ }^{\prime 1}$.

$\mathrm{Na}$ verdade, na Convenção de Estocolmo, assinada a 4 de janeiro de 1960, Portugal integra, como membro de pleno direito, o conjunto de países fundadores da EFTA, mas com um estatuto especial - Anexo G, decalcado do relatório Melander. O referido Anexo G elencava todos os benefícios que Portugal usufruiria bem como estabelecia que ficavam excluídos da EFTA os territórios ultramarinos. Deste modo, Portugal continua a poder participar na construção económica em curso na Europa Ocidental sem colocar em perigo a sua relação privilegiada com as colónias.

Ora, este argumento é utilizado com êxito pela comissão interministerial, presidida pelo Secretário de Estado para o Comércio Externo Corrêa d'Oliveira e coadjuvada pelos diplomatas Teixeira Guerra e Calvet de Magalhães para conseguir a anuência ou a compreensão do Chefe de Governo de Portugal. Assim, o compromisso alcançado salvaguardava os princípios defendidos pelo regime de Oliveira Salazar e reduzia o e isolamento internacional de Portugal.

Decididamente, a ideia de que a pertença à EFTA seria a solução ideal para Portugal, pois permitiria um compromisso entre a via da Europa e a da África, deixando a salvo o Ultramar, veio a revelar-se o ponto de viragem fundamental do eixo da política externa portuguesa. Compreende-se, assim, que em 18 de maio de 1962, o governo português solicitaria a abertura de negociações com a CEE.

Apesar de todas as dúvidas e hesitações, o facto é que Portugal iniciara a sua caminhada em direção à Europa Comunitária.

Em breve, essa aproximação tornar-se-ia inevitável numa Europa dividida em dois grupos separados. Criaram-se na Europa dois vastos espaços de comércio livre de produtos industriais, a CEE e a EFTA. Estes dois espaços obtiveram enorme sucesso comercial e económico demonstrando, desse modo que, as teorias liberais e a liberdade deveriam prevalecer sobre a filosofia que preconizava o isolamento e o protecionismo.

Em 9 de agosto de 1961, a Grã-Bretanha solicita a abertura de negociações para adesão às Comunidades ${ }^{18}$. Decisão esta que é seguida pela Dinamarca e em abril do mesmo ano pela Noruega. Muitos outros membros da EFTA, os designados por 'neutros', solicitaram também abertura de negociações embora não visassem nessa altura a adesão às Comunida-
17. ANTT, AOS/CO/EC-17-A, Pt 4, p.136.

18. AHD-MNE, EOI 207 
19. Archives Commission CCE, BAC 3/1978 n. 853/3 1957/1971

20. Consulte-se: Archives Commission CCE, BAC 3/1978 n. 102/1 19591970; Archives Commission CCE, BAC 118/1986 N. 2033; Archives Commission CCE, CEAB 5 n. ${ }^{\circ} 1420 / 1$ 1958/1964

21. Diário do Governo, $n^{0} 69$, II Série, de 23 de março de 1970. des. É o caso de Portugal que não poderia correr o risco de isolamento. Faz, então, a sua opção de fundo consciente das enormes dificuldades de natureza política, mas também de natureza económica. Por isso, manteve sempre uma posição de flexibilidade quanto à fórmula de ligação jurídica a propor à CEE.

Assim, em carta endereçada ao Presidente da CEE (18 de maio de 1962), e entregue pelo Embaixador Calvet de Magalhães, Portugal solicita a abertura de negociações com vista a "établir les termes de la collaboration entre les deux parties sous la forme considérée la plus adéquate"19.

No âmbito desta temática, é legítimo referir que o diplomata Calvet de Magalhães, após ter participado ativamente na ampliação e remodelação da OECE em OCDE, assume aí o lugar do nosso Representante Permanente. Cerca de um ano depois, em 13 de abril de 1962, já com o título honorífico de Embaixador, é nomeado primeiro Embaixador de Portugal acreditado junto da CEE e da Agência Internacional de Energia Atómica ${ }^{20}$.

Neste quadro não deixa de ser indispensável realçar a importância desta nomeação. Tratava-se de um diplomata bem aceite e conceituado nos círculos europeus, um europeísta convicto que percebeu, desde muito cedo, que o sucesso do projeto europeu radicava na matriz civilizacional europeia, na coesão dos povos da Europa e na almejada paz mundial. Mais, que Portugal, velho país europeu, não podia ser alheio a esse movimento. O discurso proferido por Calvet de Magalhães aquando da entrega de credenciais ao então Presidente da CEE, Walter Hallstein, é disso elucidativo

Assim, o Presidente do Conselho da CEE, por carta datada de 19 de dezembro de 1962, agenda a audição do caso português para 11 de fevereiro de 1963.

Lembre-se uma vez mais que continuavam as difíceis negociações entre a Grã-Bretanha e as Comunidades com vista à adesão deste país à CEE. As tentativas da Grã-Bretanha foram, porém, vetadas por De Gaulle. O afastamento de De Gaulle da presidência francesa, em abril de 1969, permitiu o renovar do pedido da Grã-Bretanha, tendo sido assinados os acordos de adesão em janeiro de 1972.

Neste contexto, o Governo português, agora chefiado por Marcello Caetano, solicita ao Presidente da Comissão da CEE, através de Memorando datado de 28 de maio de 1970, o início de negociações com a CEE no sentido de se encontrar uma forma de ligação adequada a ambas as partes.

Sublinhe-se que para a preparação de tais negociações, criou-se, por despacho conjunto do Presidente do Conselho, Marcello Caetano, do Ministro das Finanças e da Economia, João Dias Rosas e Ministro dos Negócios Estrangeiros, Ruy Patrício, datado de 23 de março de 1970, uma Comissão de Estudos sobre a Integração Económica Europeia. A esta Comissão foi atribuída a incumbência de proceder "ao estudo da situação presente e das possibilidades futuras no que respeita aos processos de participação do país nos movimentos que têm por objetivo a integração económica da Europa" ${ }^{\text {"21. }}$.

A comissão foi presidida pelo Embaixador Teixeira Guerra e pelos seguintes vogais: Calvet de Magalhães, que foi o Vice-Presidente, Alberto Nascimento Regueira, Álvaro Ramos Pereira, Carlos Lourenço, Ernesto 
Fervença da Silva, Eugénio de Castro Caldas, Ilídio Barbosa, João Cravinho, Joaquim Mexia, José da Silva Lopes que também exerceu as funções de Vice-Presidente assistido por Raquel de Bethencourt Ferreira, Luís Figueira, Rui dos Santos Martins e por João Vieira de Castro, que exerceu funções de Secretario da Comissão.

A supracitada comissão elabora, no decurso de 1970, um extenso e fundamentado relatório. Na verdade, tratava-se de um documento técnico do maior interesse como estudo rigoroso sobre as negociações com a CEE, que viriam a ser encetadas em novembro seguinte. Nele se analisam e discutem os mais diversos problemas que se colocariam a Portugal durante a sua aproximação ao Mercado Comum. Foi considerado um relatório 'revolucionário' para a época pois reconhecia, de forma muito explícita e, ao contrário da doutrina do Estado Novo, que a CEE e as suas instituições representam "o caminho mais apropriado para atingir uma razoável organização do espaço europeu [fora da órbitra soviética] possivelmente como primeira etapa duma mais demorada evolução para atingir o mais ambicioso objectivo da formação dos Estados Unidos da Europa"22. Mais: considerava que as Comunidades tinham sido fruto da ação de um "grupo de europeus de larga visão, orientados pelo primeiro Comissário do Plano francês, Jean Monnet, que começou uma corajosa campanha tendente à criação de instituições dotadas de órgãos centrais habilitados a formar e a fazer executar programas para inteligente e ordenado aproveitamento dos recursos existentes na inteira área dos territórios associados" ${ }^{32}$. O relatório considerava, também, que a Comunidade seria o mais ativo e vigoroso elemento do conjunto europeu, em contraponto à EFTA ${ }^{24}$.

Ora, esse Relatório serviria de trave - mestra a todas as negociações que se desenrolariam, em Bruxelas, com vista a estabelecer um acordo entre Portugal e a CEE. Nele, de forma muito clara, afirma-se que no âmbito das relações económicas de Portugal com a Europa, com a saída do Reino Unido da EFTA e com o consequente enfraquecimento ou desaparecimento da mesma, impunha-se a Lisboa equacionar uma forma eficaz de aproximação à CEE.

Assim, a opção mais provável seria o acordo comercial, mas seria fundamental que Portugal pugnasse por um acordo de associação. Releva-se, uma vez mais, a preservação da hipótese de uma futura adesão. Pelo que a moderação e a flexibilidade nas negociações, muito em particular no que respeitava à questão colonial, deveria ser a atitude a adotar pelo Governo português.

O enquadramento de todas as diligências exploratórias entre Portugal e a CEE, iniciadas em 24 de novembro de 1970, bem como as negociações propriamente ditas que começaram em 1971 e que se prolongaram pelo primeiro semestre de 1972, tendo culminado com a assinatura do Acordo Comercial entre Portugal e a CEE, tiveram o referido Relatório como substrato negocial.

Parece-nos interessante acentuar que apesar de todo este processo ter sido protagonizado publicamente pelo Ministro dos Negócios Estrangeiros, Rui Patrício, cuja carreira até então fora feita como Secretário de Estado do Fomento Ultramarino, todo o trabalho preparatório, todos os contactos exploratórios, toda a argumentação teórica e discursiva, ou
22. AHD-MNE/EOI/686

23. Cf. Relatório da Comissão de Estudos sobre a Integração Económica Europeia, setembro de 1970. AHD-MNE/ $\mathrm{EOI} / 686$, p. 3.

24. Cf. Relatório da Comissão de Estudos sobre a Integração Económica Europeia, setembro de 1970. AHD-MNE/ EOI/686, p. 4. 
25. Entrevista a João Rosas, Rio de Janeiro, 20 de junho de 2010.

26. Déclaration d'ouverture du Ministre des Affaires Etrangères du Portugal, $M$. Rui Patrício, au Conseil des Communautés Européennes, Bruxelles, le 24 novembre, 1970, pp. 9-13. Archives Commission CCE, BAC 3/1978 n. 853/3 1957/1971, pp. 9-10

27. AHD-MNE, EOI M. 684. seja, todo o trabalho substancial coube a Calvet de Magalhães ${ }^{25}$. No entanto, já a maior parte das negociações esteve a cargo do Ministro das Finanças e Economia, João Augusto Dias Rosas, e da sua equipa.

Registe-se ainda que o pensamento e o discurso de Dias Rosas deixam transparecer, ainda que de forma difusa, uma perspetiva de Europa que não apenas económica. Foi durante a sua gestão da pasta das Finanças e Economia que se iniciou e concluiu o último ato formal de aproximação à CEE durante o Estado Novo.

Este é, com efeito, um texto fundamental, mesmo pelos reflexos e consequências que teve na política externa portuguesa, em que o diplomata Calvet de Magalhães refere e proclama o ideal de uma adesão plena de Portugal à CEE. Nele, refere de forma explícita que as condições económicas e a própria natureza do regime não permitiam, então, que Portugal solicitasse a adesão, mas que o governo português aceitaria um acordo de associação que implicasse uma futura adesão ${ }^{26}$.

É oportuno ainda, referir que essa posição seria oficialmente reconhecida pelo Secretário de Estado do Comércio, Alexandre Vaz Pinto. Consideramos as suas palavras: a associação "é encarada pela CEE (...) como uma mera fase transitória de preparação para uma posterior adesão, retardada por razões de atraso económico ou de objecções políticas" ${ }^{\text {"27. }}$.

Expostas e aceites, assim, as pretensões portuguesas, aqui meramente enunciadas, fixou-se o dia 17 de dezembro de 1971 para início das negociações, com vista ao estabelecimento de um acordo comercial, o qual veio a ser concluído em Bruxelas, a 22 de julho de 1972 e entrou em vigor a 1 de janeiro de 1973. Para tal, foi criado, a 4 de janeiro de 1971, um Grupo de Trabalho Especial para o Estudo dos Problemas Relativos às negociações entre Portugal e a CEE do qual Calvet de Magalhães, então Director-Geral dos Negócios Económicos, foi designado Vice-Presidente e Teixeira Guerra, Presidente.

As negociações com a CEE foram dirigidas a nível político pelo Ministro dos Negócios Estrangeiros, Ruy Patrício. Como já referimos a equipa negocial foi chefiado pelo Embaixador Teixeira Guerra e a coordenação dos trabalhos, a nível técnico, esteve a cargo de Silva Lopes e a componente industrial foi da responsabilidade de João Cravinho.

Em suma, a aproximação portuguesa às instituições europeias no período de Salazar e de Marcello Caetano constituiu, com efeito, um processo longo em que as etapas se foram sucedendo e abrindo caminho para uma integração numa Europa que se queria evitar, mas que viria a ser a trave-mestra da política externa portuguesa do pós 25 de Abril de 1974.

O MNE nas negociações de adesão à CEE

No que diz respeito ao MNE, contudo, "o advento da democracia não teve, no imediato, consequências positivas" (CORREIA, 2006, p. 36), com a condução de diplomacias paralelas por vários sectores da vida política, militar e religiosa nacional aquando do período de transição e nem mesmo logo imediatamente após a entrada em vigor da Constituição de 1976. No entanto, após a tomada de posse do I Governo Constitucional, a 23 de julho de 1976, este estipulou a adesão à CEE como algo a prosse- 
guir $^{28}$, iniciando-se na vigência desse Governo toda uma série de movimentações nesse sentido, como a preparação de viagens pelas capitais dos Estados-membros (tour europeu), com vista à recolha de apoios para as pretensões portuguesas e a posterior apresentação do pedido de adesão.

Nesta fase de preparativos para solicitar a adesão tudo passou pelo MNE e pelo ministro José Medeiros Ferreira que, num contexto de incerteza e de indefinições dos Estados-membros e da opinião dos técnicos nacionais, tomou "o comando da nau da adesão", traçou "toda a estratégia diplomática da qual resultou a apresentação e a aceitação do pedido português", não se vislumbrando, nessa altura que fosse feito de modo diferente, na medida em que a diplomacia portuguesa era quem "podia ter uma apreciação realista, para além dos aspetos tecnocráticos, da posição de Portugal na Europa e das posições de cada país comunitário relativamente a Portugal”29. Todavia, após a entrega do pedido de adesão à CEE, pelo embaixador António de Siqueira Freire, a 28 de março de 1977, as negociações seriam conduzidas longe do MNE.

As implicações da adesão para os serviços apenas poderiam ser justamente avaliadas com o decurso das negociações e com a efetivação da adesão. Contudo, o fator logístico era importante numa operação tão específica, única e multiforme, pelo que deveriam ser criados os meios mínimos indispensáveis. Havia que ter em consideração nessa equação o fraco nível de desenvolvimento do país, assim como a fragilidade das suas estruturas administrativas, existindo a necessidade de congregar recursos humanos, com meios financeiros e instalações materiais adequadas, assim como de formar adequadamente técnicos. A adesão era, assim, considerada como "uma operação cuja envergadura ultrapassa de longe tudo aquilo que estamos habituados a improvisar e que requere o exercício permanente, activo e promocional da autoridade" ${ }^{130}$.

Embora a teoria da integração regional tenha negligenciado a política de alargamento da União Europeia como um tópico de interesse generalizado e permanente, conduzindo inclusive a uma escassez teórica sobre o assunto, com o alargamento de 2004 o processo de alargamento tornou-se num ponto de convergência dos interesses de investigação, inclusive na história da integração europeia, área na qual se insere o presente artigo que, por sua vez, se debruça sobre as escolhas racionais dos atores, dentro de um contexto político determinado, onde se pretende capitalizar os benefícios e minorar as perdas.

Em 1979, já as negociações de adesão haviam formalmente começado, o então Chefe da Missão de Portugal junto das Comunidades Europeias, António de Siqueira Freire, diplomata de carreira, era de opinião que, independentemente do esquema de organização das negociações a adotar do lado nacional, "haverá sempre que assegurar ao Ministério dos Negócios Estrangeiros uma função específica, visto ser esse Ministério que tem a seu cargo a coordenação da política externa em geral com a política europeia e vice-versa"31, sendo que esse entendimento vingou na parte da atribuição de "uma função específica", que sempre iria tendo no decorrer das negociações, mas não na parte da condução das mesmas.

Nesse sentido, durante os quase sete anos nos quais decorreriam as negociações (17 de outubro de 1978 a 12 de junho de 1985) foi criada toda uma estrutura de condução e de apoio às mesmas. A estrutura negocial
28. Programa do I Governo Constitucional. Disponível em: $h$ ttp://www. portugal.gov.pt/media/464012/GC01. pdf. Acesso em: 12 ago. 2018.

29. CDE-UCP, Espólio ERL, Pasta IV, "Integração europeia e política externa", Ministério dos Negócios Estrangeiros - Direcção-Geral dos Negócios Económicos, não datado, nem assinado [a assinatura sugere que seja do ministro João Freitas da Cruz, que ocupou o cargo nos IV e $V$ governos constitucionais], p. 9

30. CDE-UCP, Espólio ERL, Pasta X., "As implicações do processo de adesão às Comunidades Europeias para a orgânica dos serviços - Nota para Sua Excelência o Presidente da República", assinado por António de Siqueira Freire, Chefe da Missão de Portugal junto das Comunidades Europeias, datado de 19 de março de 1979, p. 3.

31. CDE-UCP, Espólio ERL, Pasta X., As implicações..., cit., p. 6. 
32. Decreto-lei n. ${ }^{0} 306 / 77$ de 3 de agosto. In Diário da Assembleia da República, n. ${ }^{0} 178$, I Série, de 3 de agosto de 1977

33. Decreto-lei n. ${ }^{0} 185 / 79$ de 20 de junho. In Diário da Assembleia da República, n. ${ }^{\circ} 140$, I Série, de 20 de junho de 1979 . era bastante simples: no topo da hierarquia negocial estavam o Conselho de Ministros e um ministério responsável, que delegavam na Comissão para a Integração Europeia (CIE) a preparação das negociações, sendo que, na sua base, a prestar-lhe o apoio técnico necessário, estava o Secretariado para a Integração Europeia (SIE), e em cada ministério existia um "Gabinete de Integração Europeia”, criados pelo ministro Manuel Jacinto Nunes.

Para se evitar a descoordenação das negociações, era necessário apresentar um único interlocutor por parte de Portugal. Nesse contexto, havia sido instituída, após o Conselho ter aceitado iniciar negociações, na dependência da Presidência do Conselho de Ministros, a CIE, antecessora da atual Direcção-Geral dos Assuntos Europeus, e que foi a interlocutora e coordenadora entre os diferentes ministérios, sendo da sua competência global "preparar e dirigir as negociações com vista à adesão de Portugal às Comunidades Europeias"32. No mesmo decreto no qual é constituída a CIE surge também o Secretariado para a Integração Europeia, outro dos elementos que pertencia à estrutura das negociações, e cuja finalidade é a de "apoiar a Comissão nas suas funções, nos planos técnico e administrativo", sendo das suas competências iniciais realizar estudos indispensáveis à preparação das negociações, colaborar com os serviços envolvidos nos trabalhos de preparação das negociações, e acompanhar a execução dos acordos celebrados com a CEE, de modo a garantir o seu eficaz funcionamento e o melhor aproveitamento das potencialidades respetivas ${ }^{33}$.

Dada a sua natureza essencialmente técnica e logística, tanto a CIE como o SIE, foram sempre relativamente autónomos e independentes do poder político, o que permitiu que os seus elementos não mudassem muito no decurso das negociações ao contrário do que sucedeu a nível governamental, com a sucessão de governos e respetivos responsáveis políticos pelas negociações. Assim, se a parte técnica foi mais estável, embora não isenta de vicissitudes, a condução política das negociações, com implicações para a estrutura que suportava, conheceu várias nuances, onde nunca o MNE esteve em destaque (Tabela 1.).

Tabela 1- Responsáveis políticos pelas negociações

\begin{tabular}{l|l|l}
\hline Governo & Responsável político pelas negociações & Tutela da CIE \\
\hline IV & $\begin{array}{l}\text { Vice-Primeiro-Ministro para os } \\
\text { Assuntos Económicos e Integração } \\
\text { Europeia, Manuel Jacinto Nunes }\end{array}$ & Manuel Jacinto Nunes \\
\hline V & $\begin{array}{l}\text { Ministro da Coordenação Económica } \\
\text { e do Plano, Carlos Corrêa Gago }\end{array}$ & Carlos Corrêa Gago \\
\hline VI & $\begin{array}{l}\text { Vice-Primeiro-Ministro, } \\
\text { Diogo Freitas do Amaral }\end{array}$ & $\begin{array}{l}\text { Secretário de Estado para a } \\
\text { Integração Europeia, Rui de } \\
\text { Almeida Mendes }\end{array}$ \\
\hline VII & $\begin{array}{l}\text { Ministério da Integração Europeia, } \\
\text { Alvaro Barreto }\end{array}$ & SEIE, Joaquim Ferreira do Amaral \\
\hline VIII & $\begin{array}{l}\text { Ministro de Estado e das Finanças } \\
\text { e do Plano, João Salgueiro }\end{array}$ & SEIE, José da Cruz Vilaça \\
\hline IX & $\begin{array}{l}\text { Ministro das Finanças e do Plano, } \\
\text { Ernâni Lopes }\end{array}$ & MFP, Ernâni Lopes \\
\hline
\end{tabular}

Fonte: Cunha, 2012, p. 94 
No IV GC, era competência do Vice-Primeiro-Ministro para os Assuntos Económicos e Integração Europeia, Manuel Jacinto Nunes, os assuntos relacionados com a integração europeia, cargo que será extinto no governo seguinte ${ }^{34}$, passando a coordenar esta área o Ministro da Coordenação Económica e do Plano, Carlos Corrêa Gago. Esse Governo altera, assim, o pendor da direção política das negociações para a área económica, sendo que introduz, paradoxalmente, através da aprovação do Decreto-Lei n. ${ }^{\circ}$ 185/79, de 20 de Junho, que substitui o supracitado Decreto-Lei n. ${ }^{\circ}$ 306/77, a criação do Conselho de Ministros para a Integração Europeia, "órgão ao qual passou a competir a definição das directrizes para as negociações com as Comunidades Europeias, bem como a responsabilidade por assegurar a harmonização dos diversos interesses em jogo com os objectivos visados com a integração europeia" (Correia, 2006, p. 41), estando subjacente à sua criação a urgência de se "acentuar a credibilidade externa do empenhamento do Governo Português na negociação", sendo que este deveria "ser um Conselho especial, restritivo, e não - como se disse - uma nova versão do Conselho de Ministros, com nome diferente" ${ }^{\text {"35. }}$.

Com o primeiro governo da Aliança Democrática, será conferido não só um novo impulso e uma nova determinação nas negociações, o que se verificará também a nível dos arranjos na estrutura negocial, nomeadamente com a criação da figura de Secretário de Estado para a Integração Europeia (SEIE). Diogo Freitas do Amaral, na qualidade de Vice-primeiro ministro, passa a estar responsável pela integração europeia $^{36}$, se bem que acumulava esse cargo com o de Ministro dos Negócios Estrangeiros, o que lhe permitia uma visão integrada das negociações, assim como maior visibilidade das questões de integração europeia no próprio MNE. Por essa altura, de resto, no sentido em que quer a integração europeia lato sensu e a adesão stricto sensu se enquadravam na definição global dos objetivos de política externa, o MNE já havia também adaptado a sua estrutura interna, com a criação da Repartição da Integração Europeia $^{37}$ em 1978 e nele se preconizava igualmente a necessidade da "diplomacia portuguesa dispor de instrumentos capazes de responder às novas solicitações que tem de enfrentar", assim como a premência em se organizar "em termos humanos e institucionais, os seus meios de acção no âmbito do processo de integração" 38 .

Como não tinha existido até então um Secretário de Estado encarregado das negociações, sendo essa responsabilidade em geral do ministro das Finanças e do Plano, o verdadeiro negociador tinha sido o presidente da $\mathrm{CIE}^{39}$. A grande novidade, embora sem efeitos práticos, surgiria no governo seguinte com a criação não de uma secretaria de Estado, mas de um ministério dedicado, em exclusivo, às questões europeias, facto que teve, porém, pouco relevo e não vingou, não se repetindo essa modalidade desde então. Foi escolhido para esse novo ministério, o da Integração Europeia, Álvaro Barreto. Conta-nos o próprio que essa não foi uma decisão de conferir maior importância às negociações, mas sim pelo facto do Primeiro-ministro, Francisco Pinto Balsemão, o querer como ministro e não como secretário de Estado ${ }^{40}$. Já o próprio Francisco Pinto Balsemão considera, todavia, que a adesão era "uma prioridade de tal maneira que teria que ser um 'full time job "’’11, daí a necessidade de ter um ministro.
34. Lei Orgânica do Governo Constitucional IV, 30 de dezembro de 1978 publicado no Diário da República n. 299/78 Série I $5^{\circ}$ Suplemento, Art. 3. ${ }^{\circ}$ - 1; Lei Orgânica do Governo Constitucional V, 19 de setembro de 1979, publicada no Diário da República $n^{0} .217 / 79$ Série I, art. 19. ${ }^{\circ}$.

35. CDE-UCP, Espólio ERL, Pasta III., "Informação n. . 32/79" sobre o novo Conselho de Ministros para a Integração Europeia, não datada [será posterior ao envio do decreto-lei para o Conselho de Ministros, mas anterior à publicação do mesmo], nem assinado, pp. 1-2. Esta análise vem no seguimento da pretensão do Ministro da Justiça, do dos Transportes e Comunicações, assim como das Regiões Autónomas, quererem ser incluídos nesse Conselho de ministros, juntando-se ao Primeiro-ministro, vice-primeiro ministro, Ministro das Finanças e do Plano, MNE, Agricultura e Pescas, Indústria e Tecnologia, Comércio e Turismo, Trabalho, e dos Assuntos Sociais, o que preconizava que 0 aumento do número de membros diminuiria, inevitavelmente, a sua operacionalidade e eficácia.

36. Lei Orgânica do Governo Constitucional VI, 7 de fevereiro de 1980, Diário da República n. 32/80 Série I-2, art. 3. ${ }^{\circ}-1$.

37. CDE-UCP, Espólio ERL, Pasta IV. "Repartição da Integração Europeia", Ministério dos Negócios Estrangeiros Direcção-Geral dos Negócios Económicos, não datado, nem assinado.

38. CDE-UCP, Espólio ERL, Pasta IV, Integração europeia..., cit., p. 14.

39. Vítor Constâncio, José da Silva Lopes, Vítor Constâncio de novo, Pedro Pires Miranda.

40. Entrevista a Álvaro Barreto, Lisboa 12 de janeiro de 2012.

41. Entrevista a Francisco Pinto Balsemão, Lisboa, 21 de julho de 2011. 
42. Lei Orgânica do VII Governo Constitucional, 12 de fevereiro de 1981, Diário da República, nº 36/81 Série I.

43. Entrevista a Álvaro Barreto, Lisboa 12 de janeiro de 2012

44. Orgânica do VIII Governo Constitucional, 14 de outubro de 1981, Diário da República, n. ${ }^{0}$ 236/81 Série I, art. 6. ${ }^{\circ}$.

45. Entrevista a Francisco Pinto Balsemão, Lisboa, 21 de julho de 2011
Ao Ministério da Integração Europeia (MIE), instituído oficialmente através do decreto-lei $28 / 81$ de 12 de fevereiro, competia "orientar e coordenar, sem prejuízo da competência do Ministro dos Negócios Estrangeiros e das competências próprias dos restantes Ministros, os trabalhos visando a adesão próxima de Portugal à Comunidade Económica Europeia, que se considera uma das prioridades essenciais da acção governativa" $^{\text {"\$2 }}$. No entanto, houve alguns desentendimentos iniciais entre membros do governo. André Gonçalves Pereira, então ministro dos Negócios Estrangeiros, reagiu de forma adversa a esta distribuição de competências, pois entendia que deveria ser ele e o MNE a representarem o país nas reuniões do Conselho, mantendo-se o esquema do governo anterior $^{43}$. Esta posição, contudo, nem vingou nesse governo nem nos seguintes, que agregaram a integração europeia às Finanças, apenas regressando aos Negócios Estrangeiros, onde se tem mantido, após a adesão.

Ainda as negociações estavam praticamente a começar e já tinham ocorrido todas estas alterações, que continuariam a suceder-se. Nesse aspeto, as negociações de adesão provocariam "uma alteração progressiva mas substancial nos quadros institucionais clássicos da definição e execução da política externa portuguesa" ao concentrar no Conselho de Ministros essa competência, subalternizando o MNE, e também ao criar estruturas administrativas autónomas no que diz respeito à política de integração europeia (SOUSA, 1981, p. 147). No entanto, com exceção da curta e efémera existência do MIE, com o motivo que lhe está na origem, não houve vontade política em criar um ministério autónomo, que conduzisse as negociações, alternando as mesmas entre os Negócios Estrangeiros e sobretudo as Finanças, de acordo com as prioridades selecionadas: "quando a ênfase era diplomática, a solução lógica era conceder ao MNE o papel principal; quando a urgência das adaptações internas era considerada mais importante, o Ministério das Finanças assumia esse papel" (Vilaça, 2000, p. 81); se bem que, ao longo dos sete anos de negociações propriamente ditas, a adesão foi sendo vista "quase exclusivamente como um projecto político - e aí sobretudo como um projecto da diplomacia ou da política externa” (QUADROS, 1985, p. 121), embora tal não se tivesse demonstrado efetivamente a nível da condução das negociações pelo MNE.

No governo seguinte, há um retrocesso esperado, com a extinção do MIE, pelo que a integração europeia volta a estar enquadrada numa secretaria de Estado, dependente não do MNE, como no passado, mas do Ministro de Estado e das Finanças e do Plano, com o argumento de "incorporar na estrutura económica interna, a curto e médio prazos, todas as transformações da economia portuguesa que é necessário empreender para tornar bem sucedida a adesão de Portugal à CEE"44, sendo a opção que fazia mais sentido para o então Primeiro-ministro, dado que "sendo problemas económicos faria mais sentido ser o Ministério das Finanças a dirigir as negociações em ligação com o $\mathrm{MNE}^{\prime \prime 45}$. Caberia assim a João Salgueiro, ministro, e a José da Cruz Vilaça, Secretário de Estado, a condução das negociações durante este período.

O último dos governos responsável pelas negociações, o do Bloco Central, chefiado por Mário Soares, mantém a coordenação das 
negociações no Ministério das Finanças e do Plano, superentendidas pelo ministro Ernâni Lopes, mas extingue a Secretaria de Estado da Integração Europeia ${ }^{46}$. Sobre a questão da rivalidade dos ministérios quanto à chefia das negociações, o próprio Jaime Gama, ministro dos Negócios Estrangeiros desse governo, esclarece que, na realidade "a máquina das negociações era do MNE, que tinha toda a actividade circum-negocial de pressionar e convencer os governos dos Estados-membros a avançar com as negociações, enquanto o Ministério das Finanças detinha a coordenação técnica"47, não existindo assim qualquer fricção de competências.

Por sua vez, Ernâni Lopes salienta que "a organização do Governo, no que respeita à competência política para a condução das negociações, conheceu, praticamente, todas as modalidades possíveis (desde logo, atribuída ao primeiro-ministro, ou ao ministro dos Negócios Estrangeiros com um secretário de Estado próprio; seguidamente, a um ministro específico, da integração europeia; por fim, ao ministro das Finanças e do Plano)" (LOPES, 2010, p. 28), o que, ao contrário de expectativas adversas que se pudessem ter, "não teve nenhum grande reflexo em matéria de atrasos $^{\text {"\#4 }}$ nas negociações.

Preparadas as posições negociais no país através da CIE, ganhava destaque e reconhecimento a Missão de Portugal junto das Comunidades Europeias, que servia de interligação entre o governo português e as instituições da CEE (Comissão, Conselho), e também as embaixadas nos Estados-membros, sendo que a primeira estava em contacto permanente com as segundas, das quais recebia e para as quais enviava informações acerca da evolução das negociações e sobre a perspetiva da adesão nas suas várias vertentes, evidenciando-se neste âmbito mais a participação do MNE nas negociações. Deste modo, embora não tivesse cabido ao MNE a tutela das negociações, este ia sendo informado regularmente do andamento das mesmas e exercia sobretudo a sua influência perante a Missão, que estava na sua dependência e dele recebia instruções, o que lhe permitia salvaguardar a sua participação a um nível não técnico mas político, de acordo, de resto, com a sua própria natureza.

Paralelamente, o MNE também providenciava a organização de visitas de Estado, de encontros de trabalho e de vários contactos diplomáticos bilaterais, de modo a prosseguir o objetivo da adesão fora do âmbito estritamente comunitário, expandindo-o para a esfera do relacionamento individual com cada Estado-membro.

Em todo o processo negocial destacaram-se, assim, dois ministérios, o dos Negócios Estrangeiros e o das Finanças e do Plano que, embora com diferentes atribuições e mesmo com a subalternização do primeiro em relação ao segundo na condução política das negociações, partilharam uma mesma responsabilidade: a da adesão do país à CEE. Neste processo, não contaram com muito apoio dos seus colegas ministros, na medida em que estes "não estavam muito sensibilizados para esta questão, permanecendo bastante indiferentes" ${ }^{\text {"49. }}$. De resto, também o próprio MNE "não negociava com muito entusiasmo, pois os velhos embaixadores não viam com bons olhos a integração europeia" ${ }^{\text {"50 }}$.
46. Lei Orgânica do Governo Constitucional IX de 25 de julho de 1983, Decreto-Lei n. ${ }^{\circ}$ 344-A/83, Diário da República, n. ${ }^{0}$ 169/83 Série I, $1^{0}$ Suplemento.

47. Entrevista a Jaime Gama, Lisboa, 26 de maio de 2011.

48. Entrevista a Diogo Freitas do Amaral, Lisboa, 21 de junho de 2011.

49. Entrevista a José Luís da Cruz Vilaça, Lisboa, 3 de agosto de 2011; Entrevista a José Medeiros Ferreira, Lisboa, 26 de novembro de 2011.

50. Entrevista a Diogo Freitas do Amaral, Lisboa, 21 de junho de 2011. 
Conclusão

Depois do exposto, as evidências sugerem que a aproximação de Portugal aos movimentos europeus entre 1945 e 1974 foi motivada, em grande parte, por razões e motivações de carácter económico, ou seja, o governo português e a sua política rejeitaram sempre a Europa política e todo e qualquer modelo de integração ou de supranacionalidade. Na verdade, a participação de Portugal nos movimentos de cooperação e integração no pós II Guerra Mundial resultou de condicionantes económicas e comerciais mais do que resultado de um pensamento político oficial sobre a questão da construção europeia.

Saliente-se que a história da aproximação portuguesa a esses organismos resultou também, em grande medida, do papel de certos diplomatas e funcionários, com enraizadas convicções europeias, que durante o Estado Novo desempenharam funções em lugares-chave e puderam, desse modo, influenciar o rumo dos acontecimentos bem como contribuir para o aparecimento no MNE de uma corrente internacionalista, anti isolacionista e pró-europeia.

Ora, estes funcionários do Estado português e da administração pública desejavam que a opção europeia fosse feita por Portugal, mas tal só viria a ocorrer com a Revolução de 25 de Abril de 1974 que derruba o último governo do Estado Novo dando-se a vitória da democracia e do pluralismo partidário. A consolidação da democracia e a adesão de Portugal à CEE passaram a ser os novos desígnios de Portugal.

Em termos práticos, enquanto a preparação do pedido de adesão se desenrolou no MNE, sob a alçada do ministro, a "pasta" das negociações não vai ser constante ao longo do tempo, existindo várias fórmulas distintas de coordenar as negociações, tendo a responsabilidade pelas mesmas passado pelo MNE, Ministério das Finanças e do Plano, Ministério da Integração Europeia, com o apoio da omnipresente CIE. Deste modo, enquanto na fase da preparação e da entrega do pedido de adesão, o MNE teve uma intervenção de destaque, nomeadamente no contacto com as instituições europeias e com os Estados-membros individualmente, o início das negociações irá determinar uma subalternização da sua posição, desde logo devido à sua particular apetência para uma vertente mais política, enquanto as negociações careciam de especialistas, de técnicos superiores, de diversas áreas, sendo remetida a sua coordenação para o Conselho de Ministros para a Integração Europeia.

De facto, nesta constelação, o papel desempenhado pelo MNE vai ser caracterizado no desenrolar das negociações por uma limitação dos seus poderes, sendo que a sua área de intervenção se manteve preponderante nos contactos diplomáticos a nível bilateral e com a Missão de Portugal junto das Comunidades Europeias. Após a assinatura do Acto de Adesão, a 12 de junho de 1985, iniciou-se um outro movimento, este de adaptação das estruturas negociais nacionais aos desafios da adesão, sendo disso exemplo a extinção da CIE e do SIE, assim como projetos de criação da REPER, da Comissão Interministerial de Coordenação para os Assuntos das Comunidades Europeias, da Direcção-Geral das Comunidades Europeias, no geral sobre a reorganização do $\mathrm{MNE}^{51}$. 
Referências

ARQUIVO HISTÓRICO-DIPLOMÁTICO DO MINISTÉRIO DOS NEGÓCIOS ESTRANGEIROS: $2 .^{\circ}$ P., A. 6 , M.439; $2 .^{\circ}$ P., A. 7 , M49; $2{ }^{\circ}$ P., A. 7, M.550; $2 .^{\circ}$ P., A.39, M.53; $2 .{ }^{\circ}$ P., A.40, M.238; $2 .{ }^{\circ}$ P., A. 56, M.296; OECE, $2^{\circ}$ P., 61, M.295, P.3; OECE, $2^{\circ}$ Piso ARM7M.294; PEA-M 309, não datado, não assinado.

CENTRO DE DOCUMENTAÇÃO EUROPEIA DA UNIVERSIDADE CATÓLICA PORTUGUESA (CDE-UCP) - Espólio Ernâni Rodrigues Lopes, Pasta III, "Informação n. ${ }^{\circ}$ 32/79" sobre o novo Conselho de Ministros para a Integração Europeia, não datada, não assinada.

CENTRO DE DOCUMENTAÇÃO EUROPEIA DA UNIVERSIDADE CATÓLICA PORTUGUESA (CDE-UCP) - Espólio Ernâni Rodrigues Lopes, Pasta IV, "Integração europeia e política externa”, Ministério dos Negócios Estrangeiros - Direcção-Geral dos Negócios Económicos, não datado, não assinado

CENTRO DE DOCUMENTAÇÃO EUROPEIA DA UNIVERSIDADE CATÓLICA PORTUGUESA (CDE-UCP) - Espólio Ernâni Rodrigues Lopes, Pasta IV, "Repartição da Integração Europeia”, Ministério dos Negócios Estrangeiros - Direcção-Geral dos Negócios Económicos, não datado, não assinado

CENTRO DE DOCUMENTAÇÃO EUROPEIA DA UNIVERSIDADE CATÓLICA PORTUGUESA (CDE-UCP) - Espólio Ernâni Rodrigues Lopes, Pasta X, "As implicações do processo de adesão às Comunidades Europeias para a orgânica dos serviços - Nota para Sua Excelência o Presidente da República”, assinado por António de Siqueira Freire, datado de 19 de março de 1979.

CORREIA, J. M. A integração na União Europeia e o papel do Ministério dos Negócios Estrangeiros. Nação e Defesa, N. ${ }^{\circ}$ 115, p. 29-81, 2006

CUNHA, A. O Alargamento Ibérico da Comunidade Económica Europeia: A Experiência Portuguesa.2012. Tese (Doutorado), Faculdade de Ciências Sociais e Humanas, Universidade Nova de Lisboa, Lisboa.

Entrevista a Álvaro Barreto, Lisboa, 12 de janeiro de 2012, realizada por Alice Cunha Entrevista a Diogo Freitas do Amaral, Lisboa, 21 de junho de 2011, realizada por Alice Cunha

Entrevista a João Rosas, Rio de Janeiro, 20 de junho de 2010, realizada por Isabel Maria Freitas Valente

Entrevista a José Luís da Cruz Vilaça, Lisboa, 3 de agosto de 2011, realizada por Alice Cunha Entrevista a José Medeiros Ferreira, Lisboa, 26 de novembro de 2011, realizada por Alice Cunha Entrevista a Francisco Pinto Balsemão, Lisboa, 21 de julho de 2011, realizada por Alice Cunha Entrevista a Jaime Gama, Lisboa, 26 de maio de 2011, realizada por Alice Cunha

FIGUEIRA, L. Portugal e os movimentos de cooperação e integração económica na Europa. In: VASCONCELOS, A. José Calvet de Magalhães. Humanismo Tranquilo. Lisboa: Principia, 2003, p. 39-51.

FREIRE, A.S. Os movimentos de Integração Europeia no Pós-Guerra e a Participação Portuguesa nesses Movimentos. In GUERRA, R. T.; FREIRE, A. S.; MAGALHÃES, J. C. Os Movimentos de Integração Europeia no Pós-Guerra e a Participação Portuguesa nesses Movimentos. Lisboa: INA, p. 17-31

HOCKING, B.; SPENCE, D. Foreign ministries in the European Union: integrating diplomats. Basingstoke: Palgrave Macmillan, 2002.

HOCKING, B. Foreign ministries: change and adaptation. London: MacMillan, 1999.

LEITÃO, N. A. Estado Novo, Democracia e Europa, 1947-1986. Lisboa: Imprensa de Ciências Sociais, 2007

LOPES, E. Sobre o processo negocial da adesão. Europa - Novas Fronteiras, n.26/27, p. 25-30, 2010 MAGALHÃES, C. Portugal e a integração europeia. Estratégia, n. 4, p. 33-74, 1987-1988

MAGALHÃES, C. Salazar e a unidade europeia. In: GÓMEZ, H. T. Portugal, España y Europa. Cien años de desafio (1890-1990). Mérida: Universidad Nacional de Educación a Distancia/ Centro Regional de Extremadura, 1991, p. 129-145

MAGALHÃES, J. C. Os movimentos de cooperação e integração europeia no pós-Guerra e a participação de Portugal nesses movimentos. In: GUERRA, R. T.; SIQUEIRA, A.; MAGALHÃES, J. C. Os movimentos de cooperação e integração europeia no pós-guerra e a participação de Portugal nesses movimentos. Lisboa: INA, 1981, p. 35-56 
PORTUGAL. Programa do I Governo Constitucional. Disponível em: http://www.portugal. gov.pt/media/464012/GC01.pdf. Acesso em: 12 ago. 2018

PORTUGAL. Decreto-lei n. ${ }^{\circ}$ 185/79 de 20 de junho, Diário da Assembleia da República, n. ${ }^{\circ}$ 140, I Série, de 20 de junho de 1979

PORTUGAL.Decreto-lei n. ${ }^{\circ}$ 306/77 de 3 de agosto, Diário da Assembleia da República, n. ${ }^{\circ} 178$, I Série, de 3 de agosto de 1977

PORTUGAL.Diário do Governo, nº 69, II Série, de 23 de março de 1970

QUADROS, F. Adesão às Comunidades Europeias: acordar do sonho para a realidade. Democracia e Liberdade, n. 33, p. 120-123, 1985

SOUSA, M. R. Aspectos institucionais da adesão de Portugal às Comunidades Europeias. In: AAVV. Portugal e o alargamento das Comunidades Europeias. Lisboa: Associação Portuguesa para o Estudo da Integração Europeia, 1981, p. 141-154.

TEIXEIRA, N. S.; PINTO, A. C. Portugal e a Integração Europeia, 1945-1986. Lisboa: Círculo de Leitores, 2007.

VILAÇA, J. L. C. Portugal and European integration - negotiations and legal implications. In: VASCONCELOS, A.; SEABRA, M. J. Portugal: a European story. Cascais: Instituto de Estudos Estratégicos e Internacionais/Principia, 2000, p. 79-87. 